\title{
OS DIREITOS HUMANOS E A UTILIZAÇÃO DA FORÇA NA ATIVIDADE POLICIAL
}

\author{
HUMAN RIGHTS AND THE USE OF FORCE IN POLICE ACTIVITY
}

\author{
Felipe da Silva Linhares ${ }^{1}$ \\ Tiago Vargas Guedes ${ }^{2}$ \\ Adriano Dias de Oliveira ${ }^{3}$ \\ Luiz Eduardo Mazullo Cernicchiaro ${ }^{4}$ \\ Tiago Corrêa Vargas ${ }^{5}$ \\ Elaine Cantini'
}

RESUMO: É comum veículos de mídia noticiarem diariamente crimes dos mais variados tipos, denotando um panorama da situação da segurança pública no Brasil, nesse debate, também mostram a atuação das forças policiais nas ruas, elencando casos positivos e de atuações louváveis destes profissionais, assim como ocasiões em que os mesmos não aturam corretamente, ferindo preceitos 827 constitucionais, como a dignidade dos cidadãos. Pensando nisso, o estudo pretende analisar a legalidade da utilização da força para as atividades policiais na perspectiva dos direitos humanos. Como objetivos específicos: caracterizar o termo direitos humanos a partir da Constituição, estudar o panorama atual da

${ }^{1}$ Licenciatura em Educação física pela Universidade Luterana do Brasil- ULBRA em Cachoeira do sul/ RS e pósgraduado em Administração Pública. E-mail: felipe-linhares@susepe.rs.gov.br.

${ }^{2}$ Bacharel em Administração - Universidade da Região da Campanha URCAMP - Alegrete/ RS e pós-graduado em Segurança Pública pela FAVENI.E-maill: tiago-guedes@susepe.rs.

3 Formado em História pela Unisinos e pós- graduado em Segurança Pública - FAVENI. E-mail: adrianodias@susepe.rs.gov.br.

${ }^{4}$ Bacharel em Direito pela Universidade Luterana do Brasil- ULBRA e pós- graduado em Direito Processual Civil pela UNISC.E-mail: luiz-cernicchiaro@susepe.rs.gov.br.

${ }^{5}$ Licenciatura em Educação Física - Universidade Luterana do Brasil - ULBRA - Cachoeira do Sul e pós- graduado em Administração Pública. Email: tiago-vargas@susepe.rs.gov.br.

${ }^{6}$ Bacharel em Fisioterapia- -Centro Universitário Metodista- IPA e especialista em Gestão de Sistemas Prisionais. E-mail: elaine-cantini@susepe.rs.gov.br. 
segurança pública brasileira, entender a importância da utilização da força policial em determinadas circunstâncias. $\mathrm{O}$ estudo se justifica a partir da perspectiva de que as atividades policiais são essenciais para a manutenção da harmonia social, contudo, nenhuma destas funções deve ser realizada em desconformidade com os preceitos constitucionais, especialmente de respeito a dignidade da pessoa, que se relaciona diretamente com os direitos humanos. A partir disso, se levanta a seguinte problemática: é possível a efetivação do válido direito de uso da força nas atividades policiais sem desrespeitar os direitos humanos? Para atingir os objetivos citados, a pesquisa tem fundamentação teórica a partir de uma revisão de literatura de abordagem qualitativa, em estudos relacionados à segurança pública, uso da força na atividade policial e do panorama que cerca a segurança pública brasileira.

PALAVRAS-CHAVE: Sistema prisional. Ressocialização. Sociedade.

ABSTRACT: It is common for media outlets to daily report crimes of the most varied types, denoting an overview of the situation of public security in Brazil. as occasions when they do not act correctly, hurting constitutional precepts, such as the dignity of citizens. With this in mind, the study aims to analyze the legality of the use of force for police activities from the perspective of human rights. As specific objectives: to characterize the term human rights from the Constitution, to study the current panorama of Brazilian public security, to understand the importance of using the police force in certain circumstances. The study is justified from the perspective that police activities are essential for the maintenance of social harmony, however, none of these functions should be performed in noncompliance with constitutional precepts, especially with respect to the dignity of the person, who is directly related to human rights. From this, the following problem arises: is it possible to enforce the valid right to use force in police activities without disrespecting human rights? In order to achieve the aforementioned objectives, the research has a theoretical basis based on a literature review with a qualitative approach, in studies related to public security, the use of force in police activity and the panorama that surrounds Brazilian public security.

Keywords: Prison system. Resocialization. Society.

\section{INTRODUÇÃO}

A segurança pública é um dos preceitos promulgados na Constituição brasileira de 1988, onde qualquer cidadão, independentemente das suas condições sociais, econômicas, crenças religiosas ou etnia, tenha assegurada a sua segurança, com liberdade para ir e vir. Mas nem sempre este importante aspecto da Constituição é efetivado, fazendo surgir a necessidade de intervenção policial, para que os limites do direito não sejam desrespeitados por transgressores.

É comum, veículos de mídia noticiarem diariamente crimes dos mais variados tipos, denotando um panorama da situação da segurança pública no Brasil, nesse debate, também mostram a atuação das forças policiais nas ruas, elencando casos positivos e de atuações louváveis destes profissionais, assim 
como ocasiões em que os mesmos não aturam corretamente, ferindo preceitos constitucionais, como a dignidade dos cidadãos.

Dessa forma, o estudo pretende analisar a legalidade da utilização da força para as atividades policiais na perspectiva dos direitos humanos. Como objetivos específicos: caracterizar o termo direitos humanos a partir da Constituição, estudar o panorama atual da segurança pública brasileira, entender a importância da utilização da força policial em determinadas circunstâncias.

A pesquisa se justifica a partir da perspectiva de que as atividades policiais são essenciais para a manutenção da harmonia social, contudo, nenhuma destas funções deve ser realizada em desconformidade com os preceitos constitucionais, especialmente de respeito a dignidade da pessoa, que se relaciona diretamente com os direitos humanos. A partir disso, se levanta a seguinte problemática: é possível a efetivação do válido direito de uso da força nas atividades policiais sem desrespeitar os direitos humanos?

Para atingir os objetivos citados, a pesquisa tem fundamentação teórica a partir de uma revisão de literatura de abordagem qualitativa, em estudos relacionados à segurança pública, uso da força na atividade policial e do panorama que cerca a segurança pública brasileira.

Sendo assim, o estudo traz inicialmente uma discussão e caracterização dos direitos humanos, a partir de uma discussão sobre dignidade da pessoa humana, todos presentes na Constituição. Depois, é feito uma deliberação acerca da conjuntura atual da segurança pública brasileira, dando suporte para o entendimento da importância e características das polícias, especialmente a militar, descrevendo a relevância da utilização da força em determinadas circunstâncias.

\section{A CONSTITUIÇÃO E OS DIREITOS HUMANOS}

A Constituição estabelece diversos aspectos que devem ser considerados basilares para todos os cidadãos. Estes são os chamados direitos fundamentais, dentre estes, o acesso à educação, a tratamento médico, moradia, alimentação e o foco do presente estudo, que é a segurança. Seguir todos esses preceitos, são imprescindíveis para a garantia da dignidade de cada cidadão.

Os direitos humanos é uma série de garantias que também se envolvem com estes aspectos citados, haja vista que está centralizado na dignidade da pessoa humana, no respeito da sua integridade, formando assim direitos relacionados e basilares. Os direitos humanos se configuram como uma 
premissa do início do século XX, ganhando força ao longo dos anos e se estabelecendo constitucionalmente em 1988, com a promulgação da carta magna. Como citado:

O princípio da dignidade da pessoa humana, que ganhou força, principalmente, após a Segunda Guerra Mundial com a Declaração Universal dos Direitos Humanos da Organização das Nações Unidas (ONU) de 1948, e foi desenvolvido, primeiramente, em países da Europa como, por exemplo, a Alemanha, foi elevado a princípio fundamental pela Carta da República do Brasil de 1988, ganhou, também, grande destaque nos ordenamentos jurídicos de vários países (CARVALHAES, 2014, P.I)

Embora os direitos humanos sejam frequentemente citados, e colocado como aspecto primordial para a efetivação de garantias inerentes a natureza humana, não existe um consenso concreto, nem uma definição precisa do que se caracteriza os direitos humanos. O que pode ser afirmado, é que os direitos humanos se refletem de forma direta no ramo do direito, servindo como embasamento para a criação de leis, assegurando determinados direitos e deveres a todos os cidadãos, assim como para o Estado, que deve intermediar as relações, dando segurança jurídica e tutela nos casos em que seja necessário (CARVALHAES, 2014).

No Brasil, são recorrentes as discussões têm como foco os direitos humanos, relacionando a mesma diretamente a segurança pública. Cabe dizer que os direitos humanos não são apenas de questões relacionadas a criminalidade, de proteção ou não se certas categorias sociais (ASSIS, et al., 2015).

Os veículos de mídia, nas suas mais variadas formas, mais especialmente nos chamados jornais policiais, insistem em tornar bastante rasa a discussão a respeito do tema, tornando frequente as retóricas de que os direitos humanos se caracterizam como uma espécie de proteção para infratores, que abrem margens ou brechas para ilegalidades na segurança pública, ou no sistema carcerário, a chamada “proteção aos bandidos”, contudo, o debate é muito mais amplo (ASSIS, et al., 2015).

Um exemplo prático, é a conjuntura nas prisões. O cenário carcerário brasileiro, tem como característica a completa ausência de estrutura, com superlotação, falta de condições sanitárias e insegurança, inclusive jurídica. Ou seja, todos esses fatores se configuram como uma completa afronta aos direitos constitucionais, pois cabe ao Estado zelar pela dignidade de todos os cidadãos, inclusive daqueles inseridos no sistema prisional (SOUZA, 2015)

Ou seja, o Estado tem sim, o dever de punir os infratores, mas essa punição se resume a privação de liberdade, jamais, expondo qualquer cidadão, independentemente da infração que tenha cometido, a situações degradantes, que venham a ferir a dignidade do sujeito. Ocorre então que os direitos humanos não estão centralizados nessa discussão, mas o atual cenário desta conjuntura, fomenta discursos nesse sentido (ASSIS, et al., 2015) 
Com isso, se criam cenários propícios para discursos sem fundamentos, endossados também por representas políticos, que usam essa importante discussão como bandeira ideológica. Deste modo, é preciso que o poder público repense suas estratégias de segurança pública, visando mitigar os altos índices de criminalidade, sem trazer detrimentos a preceitos constitucionais.

\section{CONJUNTURA ATUAL DA SEGURANÇA PÚBLICA}

A desigualdade social se caracteriza como um dos graves problemas para o Brasil, a ausência de políticas públicas eficazes nessa direção, fomenta injustiças, enquanto uma considerável parcela da sociedade, não tem acesso a condições básicas de subsistência. A falta de condições para acessar uma educação de qualidade, atendimento médico, ausência de alimentação e moradia adequadas, são fatores que fomentam injustiças e revoltas, fazendo com que alguns busquem meios tortuosos para conseguir aquilo que precisam (MARTINS, 2014).

Obviamente, não existe um modo concreto de estabelecer quais as razões que tornam os índices de criminalidade no Brasil, altos, mas existem determinados fatores que invariavelmente impulsionam o aumento da complexidade de resolução destes graves problemas sociais e de segurança pública (SOUZA, 2015).

Nesse sentido:

O fenômeno da criminalidade e violência urbana no Brasil é uma das questões sociais mais relevantes no quadro das políticas públicas requerendo reformas estruturais e mudanças na sociedade, especificamente com iniciativas ao aprimoramento das instituições de segurança pública. A escalada da violência, da criminalidade e das diversas violações dos direitos humanos impõe a crescente necessidade de realizar estudos e diagnósticos, que permitam formular agendas de prioridades e elaborar planos de ação para reduzir o cenário de insegurança instalado na sociedade brasileira. Nessa perspectiva, é indispensável implementar ações de elaboração, consolidação e difusão de conhecimentos no campo da segurança pública (MARTINS, 2014, p.19)

Estudiosos de alguns setores, como o supramencionado, acreditam que um dos elementos importantes para a redução dos índices de violência, está na reestruturação das forças policiais, que devem primar por ações mais pedagógicas, em detrimento do uso da força. Esse debate ainda se torna mais amplo e complexo, quando se discute os diferentes tratamentos dados pela polícia, especialmente a militar, as parcelas menos vulneráveis da população.

Segundo Araújo (2017) existe uma tendência muito maior de utilização da força por parte da polícia, em comunidades carentes, onde os índices de criminalidade sejam maiores. Entretanto, nos 
locais mais privilegiados economicamente, as ações da polícia de trabalho ostensivo, são mais brandas, de cunho pedagógico. É complexo sintetizar de forma coesa quais os fatores que fazem com que haja esse tipo de cenário, o que se sabe, é que é algo que precisa ser aprimorado, pois, as estratégias mais educativas devem ser primadas em detrimento do uso da força.

Diversos outros fatores também devem ser considerados dentro dessa discussão, como, por exemplo a difusão crescente do uso de drogas pelas cidades brasileiras, principalmente nas grandes metrópoles. O consumo de drogas ilícitas nas cidades trazem uma série de problemas, que ocasiona uma reação em cadeia (GUIMARÃES, 2015).

Quando um indivíduo ingressa nessa conjuntura degradante, as consequências são devastadores, não somente par o indivíduo, mas para toda a gama de pessoas que a cerca, trazendo efeitos também para a coletividade. UM usuário de drogas, é uma pessoa com maiores chances de cometer atos ilícitos para o sustento do vício ilegal, pois nessas circunstâncias dificilmente conseguirá sustentar o vício através de vias legais (GUIMARÃES, 2015).

Ocorre que para esse quandro ser reduzido, impactando positivamente, é necessário estratégias de segurança pública de médio e longo prazo. Isso se deve ao fato de que as drogas representam um problema não só de segurança, mas também de saúde pública. Araújo (2017) afirma que, o problema das drogas não se mostra perto do fim, pois as estratégias estatais para a resolução deste complexo cenário, se resume a ações repressivas da polícia, tratando esses dependentes químicos como simplesmente delinquentes. Ou seja, se tenta mitigar esse problema por meio da utilização da força.

Esse tipo de ação por parte do poder público, se mostra equivocada por dois tipos em especial, seja por ir contra preceitos constitucionais que envolvem a dignidade e os direitos humanos, além de ser algo paliativo, e não um recurso de médio a longo prazo para a redução do número de dependentes químicos e consequentemente a diminuição dos índices de violência ocasionados pelas drogas (GUIMARÃES, 2015).

A utilização da força em excessividade nas ações policiais, mostra a ineficiência do Estado no controle e manutenção da segurança pública, pois este tipo de recurso, deve ser a última estratégia no combate a problemas de violência.

Mas um fator intrigante nesse cenário, é de que não é a ausência de recursos financeiros que dificulta estratégias mais amplas e eficazes na segurança pública, pois embora seja um setor da sociedade 
oneroso para os cofres do Estado, a nível municipal, estadual e federal, o que se percebe, é a ineficácia da utilização dos recursos financeiros.

Nesse sentido:

Seja como for, o país gasta o equivalente a países desenvolvidos e nem por isso consegue reverter o quadro de medo e insegurança, muito em função de um modelo falido de organização policial e administração de conflitos. Como dito na introdução, é possível supor que o crescimento dos gastos com segurança pública é um efeito inevitável de se optar por manter um sistema disfuncional na prevenção da violência e na garantia de direitos e que, para continuar de pé, exige volumes crescentes de investimentos.Todavia, essa opção não se dá pelo sucesso desse sistema em fazer cumprir o monopólio estatal da violência e oferecer serviços de qualidade. Ao contrário, ela parece guardar mais relação com os sentidos e prioridades políticas que o tema assume para os dirigentes políticos (LIMA, 2016, p.6).

A segurança pública precisa ser pensada amplamente, as estratpegias do poder público precisa ser pensada a longo prazo, e a força policial deve estar em conformdiade e sintonia com as estratégias lançadas. Isso se acentua, se considerar as possíveis contribuições que uma modificação de mentalidade na condução da polícia militar pode trazer, haja vista que o maior contato com o público, as ações ostensivas e preventivas são realizadas por esse órgão do governo.

\section{IMPORTÂNCIA E CARACTERÍSTICAS DAS FORÇAS POLICIAIS}

As atividades das forças policiais são altamente relevantes para a construção de uma harmonia social, pois a Constituição e demais textos de lei, estabelecem as regras para o convívio em sociedade, mas sempre existem aqueles que atuam à margem destas regras, cometendo atos ilícitos.

A partir destas perspectivas, fica expressa a importância da atividade policial, que deve vigiar e se fazer cumprir as regras estabelecidas pela legislação. Ocorre que nem sempre os meios pedagógicos são suficientes para conter as ações ilegais, e se faz importante a utilização da força.

Porém, em determinados casos é necessário e importante que os policiais utilizem a força:

$\mathrm{Na}$ nossa sociedade, para condicionar o uso e o gozo dos bens, atividades e direitos individuais, em benefício da coletividade e do próprio Estado, os agentes encarregados de aplicar a lei podem recorrer ao atributo administrativo da coercibilidade, diante do seu entendimento da conveniência e oportunidade de agir, independente de ordem judicial. Entre esses agentes, estão incluídos principalmente aqueles ligados à segurança pública, uma vez que estes portam a permissão para o uso da força e das armas, o que lhe confere natural e destacada autoridade para a pacificação social. A este poder, denomina-se Poder de Polícia (FAGUNDES, 2018, p.8) 
A grande questão e dicotomia da utilização da força por parte dos policiais, está na escolha do momento correto para fazer uso desse tipo de ação. $O$ trabalho do policial militar consiste em prevenir e patrulhar, mas também de atuar de forma prática nas ocasiões em que se fizer necessário.

Contudo, nem todos os momentos permitem uma atuação pacífica por parte dos agentes, sendo necessário tomar medidas mais duras, que possam causar detrimentos para a integridade física e moral daquele que está comentendo um ato ilícito. Como salientado em outros momentos do estudo, a dignidade de qualquer cidadão deve ser respeitada, mas nas hipóteses que a ação de um sujeito, traga prejuízos para os direitos de terceiros, ou do patrimônio público e privado, cabe a polícia intervir, objetivando o bem-estar da coletividade em detrimento daquele que está agindo em desconformidade com a legislação.

Cabe dizer então, que o bem-estar social, ou seja, da coletividade, deve ser objetivo central das ações policiais, mesmo que pra isso seja necessário agir de forma mais abrupta com alguém que está a atuar incorretamente. Assegurar a dignidade de cada cidadão, está diretamente atrelado aos direitos humanos, devendo ser uma política de estado e de segurança pública.

Mas para que tudo isso seja efetivado e que os índices de criminalidade sejam reduzidos, assim como a utilização de força por parte da polícia seja cada vez maior, é preciso que políticas públicas de médio e longo prazo sejam efetivadas, com respeito aos direitos humanos, sem deixar de lado a atenção e o cuidado com a coletividade. Mas para isso se concretizar, as mudanças precisam ser profundas, envolver aspectos de saúde pública e diminuição das desigualdes sociais, com maior acesso à educação e oportunidades a nível social, pois somente assim o país poderá colher frutos a longo prazo, onde as populações mais vulneráveis tenham mais condições de se inserir corretamente na sociedade, evitando a criação de cenários propícios para a criminalidade.

\section{CONSIDERAÇÕES FINAIS}

O presente estudo, objetivou discorrer sobre a utilização da força pela polícia na conjuntura do respeito aos direitos humanos. Inicialmente foi trazido uma abordagem acerca dos chamados direitos fundamentais, que envolvem o respeito a questões básicas de existência do homem, como acesso à educação, saúde, alimentação e segurança. Todos esses fatores são importantes para a garantia da dignidade do homem, fator primordial para o respeito dos direitos humanos. 
Embora os direitos humanos estejam presentes nos textos de lei do país, inclusive na própria Constituição, ainda existe por parte de algumas correntes ideológicas, a crença de que os direitos humanos são fatores incorretos, destinados a proteção de infratores em detrimento da grande população. Entretanto, a partir da deliberação de diferentes estudos e reflexões de pesquisadores, ficou claro que a questão dos direitos humanos é muito mais ampla, envolve uma série de garantias relevantes e descritas pela Constituição, sendo necessário o seu respeito na íntegra, mesmo para aqueles que cometeram algum ato ilícito e se encontram em cumprimento de penas em unidades prisionais, por exemplo.

A partir disso, o estudo trouxe um panorama acerca da atual conjuntura da segurança pública no Brasil. Nesse sentido, ficou evidenciado alguns preocupantes fatores acerca desse complexo problema, como a desigualdade social no país, que fomenta injustiças e revoltas, dando maiores, possibilidade da formação de pessoas transgressoras da lei, que buscam através de atos ilícitos satisfazer as suas necessidades.

Um dos graves problemas que mostram a gravidade ocasionada por essa desigualdade, é o alto índice de pessoas dependentes de drogas, que entram nesse submundo impulsionadas pela falta de oportunidades. Ocorre que esse tipo de conjuntura, impacta não só a saúde pública, como a segurança pública, fazendo com que as ações policiais, inclusive da utilização da força, cresçam de forma gradativa.

Por fim, o estudo procurou discorrer sobre as circunstâncias em que se torna plausível a utilização da força por parte das autoridades policiais. Isso ocorre principalmente nas ocasiões em que a atitude de um sujeito, coloca em risco direitos de outros, seja a sua integridade física, ou a seu patrimônio, o mesmo também pode ocorrer nas circunstâncias de risco e depredação de patrimônio público.

Mas cabe ressaltar que o uso da força jamais deve ser a ação primária das forças policiais, atitudes de cunho pedagógico deve sempre ser a primeira ideia das forças policiais, sendo que a força deve ser então o último recurso a ser utilizado. Outro importante fator, é que a ação policial deve ter uma uniformidade, ou seja, as mesmas estratégias utilizadas na abordagem de pessoas de classes econômicas e sociais menos favorecidas, também deve ser utilizada nas áreas nobres. Isso é uma forma de mostrar que todos os cidadãos são iguais perante as leis e as autoridades, e que condições financeiras, classe social ou local de moradia, não sirvam como parâmetros para definir a índole de alguém.

A problemática do presente estudo, envolvia a análise se é possível a efetivação do válido direito de uso da força nas atividades policiais sem desrespeitar os direitos humanos. Sobre essa questão, o estudo mostrou ser possível sim, estes dois fatores caminharem conjuntamente, entretanto, o bem-estar 
da coletividade deve sempre ser privilegiado em detrimento da individualidade de um cidadão. Ou seja, nos casos em que alguém colocar em perigo outras pessoas, o mesmo se coloca à mercê da utilização da força por parte dos policiais.

Deste modo, é possível enfatizar que os objetivos propostos pela presente pesquisa foram alcançados, enquanto ficou caracterizado o que se configura os direitos humanos, assim como da sua importância para a efetivação da dignidade da pessoa humana. Além disso, foram trazidos importantes conceitos acerca da utilização da força na atividade policial, explicitando em quais ocasiões está se faz necessária, mas asseverando que ações de cunho pedagógico devem ser as estratégias iniciais, objetivando trazer menos danos a integridade física de qualquer cidadão.

\section{REFERÊNCIAS}

ARAÚJO, José Carlos Evangelista de. O estado social democrático de direito em face do princípio da igualdade. [Mestrado] Pontifícia Universidade Católica de São Paulo, 2017. Disponível em: <http://www.dominiopublico.gov.br/download/teste/arqs/cp032III.pdfAcesso em: 30 de março de 202I.

ASSIS, Simone Gonçalves de. Et. al. A imagem do policial frente a sociedade. Coleção Segurança com Cidadania [Volume I] Subsídios para Construção de um Novo Fazer Segurança Pública, São Paulo, 2015. Disponível em: < https://www.novo.justica.gov.br/sua-seguranca-2/seguranca-publica/analise-epesquisa/download/estudos/sjcvolumeI/imagem_policial_midia_escrita_estudo_comparativo_quatro_c apitais.pdf $>$ Acesso em: 30 de março de 2021

CARVALHAES, Paulo Sérgio. Princípio da dignidade da pessoa humana e os seus reflexos no direito brasileiro. Parte Geral e LINDB. II ed. Salvador: Juspodivm, 2014. Disponível em: 〈https://revistacientifica.facmais.com.br/wp-nt/uploads/2015/o8/artigos/principio_da_dignidade.pdf〉 Acesso em: 30 de março de 202I.

FAGUNDES, Diego Araújo Fernandes. Uso legal e progressivo da força na atividade policial. Jus Navigandi, Teresina, ano 7, n. 56, I abr. 2018

GUIMARÃES, Sérgio Antônio. Racismo e anti-racismo no Brasil. Editora 34, São Paulo, 2015

LIMA, Renato Sérgio de. Estado, polícias e segurança pública no Brasil. V. I2 N. I Revista Direito JV, Jan- Abr, 2016

MARTINS, Herbert Toledo. Criminalidade, direitos humanos e segurança pública. Editora UFRB, Cruz das Almas, 2014

SOUZA, Laura Guedes de. Análise jurídica do sistema penitenciário brasileiro à luz dos tratados internacionais em direitos humanos. Revista Direito em Ação, Brasília, v. I4, n. I, p. I - 21, jan./jun.2015. 